\title{
PENGARUH TEKNIK PERNAPASAN BUTEYKO TERHADAP KONTROL ASMA BRONKIAL
}

\section{The Effect Of Buteyko Breathing Tecnique To Control Astma Bronchiale}

\author{
Marlin Sutrisna $^{1}$, Emmy H Pranggono ${ }^{2}$, Titis Kurniawan ${ }^{3}$ \\ ${ }^{1}$ Universitas Dehasen Bengkulu \\ ${ }^{2,3}$ Dosen Fakultas Keperawatan Universitas Padjadjaran \\ Email korespondensi : marlinsutrisna@yahoo.co.id
}

\begin{abstract}
ABSTRAK
Asma bronchial merupakan masalah kesehatan yang serius dengan tingkat kekambuhan yang tinggi. Terapi farmakologi jangka panjang berpotensi menimbulkan efek samping seperti peningkatan enzim hati, sakit kepala, mual, supresi adrenal, osteopenia, dan kematian. Di sisi lain teknik pernapasan buteyko dapat memperbaiki fungsi paru, meningkatkan oksida nitrat, melembabkan dan menghangatkan udara yang berpotensi menurunkan gejala asma dan konsumsi obat-obatan. Penelitian ini bertujuan untuk mengetahui pengaruh teknik pernapasan buteyko terhadap kontrol asma. Penelitian quasi eksperimental dengan pendekatan pretest and post test one group design ini melibatkan 14 pasien asma yang dipilih dari Poli Paru RSUP Dr. Hasan Sadikin Bandung dengan consecutive sampling. Kontrol asma dikumpulkan dengan menggunakan Asthma Control Test (ACT) secara time series dan pemeriksaan spirometri (nilai FEV1) pada pretest dan post test minggu ke empat. Data yang terkumpul dianalisis secara deskriptif dan inferensial dengan skala signifikansi $p<0,05$. Uji paired t-test menunjukkan terdapat perbedaan yang signifikan $(p=0,00)$ antara nilai FEV1 setelah diberikan teknik pernapasan buteyko $(69,57 \pm 6,836)$ dengan nilai FEV1 sebelum diberikan teknik pernapasan buteyko $(37,43 \pm 6,513)$. Uji Repeated ANOVA menunjukkan adanya perbedaan yang signifikan $(\mathrm{p}=0,00)$ antara skor ACT setelah diberikan teknik pernapasan buteyko $(19,79 \pm 1,47)$ dengan skor ACT pada minggu III $(17,50 \pm 1,78)$, minggu II $(12,64 \pm 1,82)$, minggu I $(9,57 \pm 1,95)$, dan pretest $(7,64 \pm 1,82)$. Post hoc analisis menemukan skor post test minggu ke empat $(19,79 \pm 1,47)$ signifikan lebih tinggi daripada posttest minggu III $(17,50 \pm 1,78)$, minggu II $(12,64 \pm 1,82)$, minggu I $(9,57 \pm 1,95)$, dan pretest $(7,64 \pm 1,82)$. Disimpulkan bahwa ada pengaruh yang positif teknik pernapasan buteyko terhadap kontrol asma. Dengan demikian, penting menjadikan hasil penelitian ini sebagai bahan telaah bagi petugas kesehatan di Rumah Sakit dalam upaya peningkatan kontrol asma.
\end{abstract}

Kata kunci: asma bronkial, buteyko, teknik pernapasan

\section{ABSTRACT}

Bronchial asthma is a serious health problem with high recurrence rates. Long-term pharmacological therapy has the potential to cause side effects such as elevated liver enzymes, headache, nausea, adrenal suppression, osteopenia, and death. On the other hand the buteyko breathing technique can improve lung function, decrease asthma symptoms, drug use, thus improving asthma control. This study aims to determine the effect of buteyko breathing technique on asthma control. The quasi experimental study with the pretest and post test one group design approach involves 14 patients with asthma selected from the Lung Polyclinic of Dr. Hasan Sadikin Bandung with consecutive sampling. Asthma control was collected using time series ACT and spirometry examination (FEV1 value) in pretest and post test week four. The collected data were analyzed descriptively and inferentially with 
the scale of significance $p<0.05$. The results showed a significantly higher mean difference between ACT scores after buteyko breathing technique (19.79 \pm 1.47$)$ with ACT score at week III (17.50 \pm 1.78), week II (12.64 \pm 1.82$)$, week I (9.57 \pm 1.95$)$, and pretest (7.64 \pm 1.82$)$. Post hoc analysis found the fourth week post test score (19.79 \pm 1.47$)$ significantly better than post test week III (17.50 \pm 1.78$)$, week II (12.64 \pm 1.82$)$, week I (9.57 \pm 1.95$)$, and pretest (7.64 \pm 1.82$)$ in improving asthma control. The paired t-test showed that there was a mean FEVI value after the buteyko breathing technique was significantly higher than the score before the buteyko breathing technique was administered. It was concluded that there was an effect of buteyko breathing technique on asthma control. Thus, the results of this study become important as a study material for nurses at the Hospital in an effort to increase asthma control.

Keywords : asthma bronchiale, breathing technique, buteyko

\section{PENDAHULUAN}

Asma bronchial merupakan masalah kesehatan yang serius dengan prevalensi yang cukup tinggi dan terus menjadi masalah kesehatan masyarakat yang utama di seluruh dunia (To et al., 2013). Diperkirakan sebanyak 334 juta orang mengalami asma dari segala usia di seluruh belahan dunia (Global Asthma Network, 2014). Pada tahun 2025 diperkirakan penyakit asma di dunia mengalami peningkatan sampai 400 juta orang (Masoli, Fabian, Holt, \& Beasley, 2004). Sedangkan menurut Riset Kesehatan Dasar Tahun 2013 penyakit asma menempati angka tertinggi untuk kategori penyakit yang tidak menular di Indonesia sebesar $4,5 \%$ dan penyakit ini lebih banyak dialami oleh perempuan (Riskesdas, 2013).

Asma dapat mempengaruhi baik fisik maupun psikologis pasien. Dampak negatif dari penyakit asma dapat menyebabkan gangguan pola tidur, aktivitas sehari-sehari, kerusakan paru, dan terjadinya komplikasi asma (Li et al., 2005). Asma menyebabkan kecemasan dan depresi pada pasien. Kecemasan tersebut disebabkan oleh konsumsi kortikosteroid dan meningkatnya jumlah hari rawat inap di rumah sakit (Kullowatz, Kanniess, Dahme, Magnussen,
\& Ritz, 2007). Selain memberikan dampak fisik, psikologis, ataupun fungsional, asma juga dapat mempengaruhi kualitas hidup penderitanya bahkan dapat meningkatkan angka morbiditas (To et al., 2013). Penurunan kualitas hidup pasien asma dipengaruhi oleh kecemasan dan depresi (Kullowatz et al., 2007).

Penyakit asma termasuk penyakit yang berdampak besar pada aspek ekonomi, karena pasien dengan asma membutuhkan biaya yang cukup besar untuk biaya medis seperti rawat inap dan obat-obatan bahkan menyebabkan kematian dini (Masoli et al., 2004). Peningkatan pengeluaran biaya pengobatan yang dikarenakan oleh kontrol penyakit yang lebihketat(Dal Negro et al., 2007). Sekitar 16,1 miliar dolar biaya yang dikeluarkan untuk perawatan (Black \& Hawks, 2014). Asma juga menyebabkan kehilangan hari kerja akibat mengalami kekambuhan (Dal Negro et al, 2007).

Menurut Bateman et al (2008), penatalaksanaan asma yang utama adalah mempertahankan kontrol asma dengan pendekatan manajemen asma yang baik seperti kerjasama antara pemberi pelayanan kesehatan dengan pasien, memanajemen diri, dan menetapkan tujuan dalam pengobatan. Tetapi penatalaksanaan 
asma bronkial yang saat ini digunakan dengan pemberian terapi farmakologi, karena dapat membantu mengurangi atau meredakan serangan asma bronkial, seperti terapi bronkodilator, kortikosteroid. Kombinasi kedua obat tersebut (Long acting B2 agonist + inhaled kortikosteroid) terbukti efektif untuk menangani penyakit asma bronkial karena kedua obat ini dapat mengurangi eksaserbasi dan memperbaiki fungsi paru. Selain itu kombinasi ICS/long acting 32 agonis lebih banyak disukai orang dewasa (Fm, M, Greenstone, dan $\mathrm{Tj}$, 2010). Menurut Higashi, Zhu, Stafford, dan Alexander (2011), terjadi peningkatan penggunaan steroid inhalasi dan kombinasi steroid/long acting $\beta 2$-agonis digunakan bertepatan dengan penurunan morbiditas dan mortalitas asma.

Kelemahan dari penggunaan terapi farmakologi jangka panjang yaitu memiliki efek samping terutama jika tidak dilakukan pengontrolan dalam pengobatan. Penggunaan kortikosteroid inhalasi beresiko memberikan efek samping seperti penekanan pertumbuhan pada anak-anak, peningkatan enzim hati, sakit kepala, mual, supresi adrenal, osteopenia, dan kematian, sedangkan obat anti-leukotrien memiliki resiko/efek lebih rendah untuk menyebabkan efek samping tersebut (Ducharme \& Chauhan, 2014). Menurut Thomas (2004), penggunaan obatanobatan jangka panjang memiliki masalah finansial atau pengeluaran biaya yang cukup mahal. Penggunaan obat-obatan asma seperti bronkodilator yang terlalu sering (ketergantungan) dapat menjadi kontra produktif dan berkontribusi untuk meningkatkan kematian.

Untuk mencegah terjadinya komplikasi dari pengobatan asma maka diperlukan pembaharuan dalam terapi asma dengan memberikan terapi pendamping (nonfarmakologi). Tujuan dari terapi nonfarmakologi untuk mencapai gaya hidup yang normal, menghindari serangan, dan mengembalikan fungsi paru yang optimal (Bruurs, Van Der Giessen, \& Moed, 2013). Terapi nonfarmakologi yang diberikan pada pasien asma adalah teknik pernapasan buteyko, senam asma atau latihan, dan yoga. Menurut Heikkinen, Quansah, Jaakkola, dan Jaakkola (2012), latihan fisik secara teratur dapat meningkatkan kebugaran fisik yang diukur dari konsumsi oksigen yang maksimal pada pasien asma. Namun pada penelitian ini, tidak memberikan efek positif terhadap fungsi paru. Menurut Ai, Hoang, dan Nguyen (2015), terapi yoga memberikan efek pada pernapasan seperti perbaikan FEV1 dan PEFR. Terapi yoga ini memberikan efek yang signifikan setelah dilakukan intervensi selama 3 bulan. Penelitian ini didukung oleh Mariya, Rashmi, Amita, dan Amita (2013), bahwa yoga memberikan manfaat yang positif pada pasien asma. Namun terapi yoga tidak menunjukan perbaikan volume paksa vital (FVC).

Dibanding terapi nonfarmakologi lainnya, teknik pernapasan buteyko memiliki kelebihan yaitu aman dan mudah dilakukan (Hassan et al, 2012). Selain itu dapat menghangatkan, memfiltrasi, dan melembabkan udara yang masuk, dan meningkatkan produksi oksida nitrat (Bruton \& Lewith, 2005). Teknik pernapasan ini dapat menurunkan gejala asma, dan penggunaan obat-obatan (Cooper et al., 2003). Hal ini didukung oleh Solomen dan Aaron (2016), latihan pernapasan meningkatkan volume paru, pertugaran gas, mengontrol sesak napas, dan membantu membersihkan sekresi. 
Penelitian yang dilakukan oleh Hassan, Riad, dan Ahmed (2012), didapatkan bahwa teknik pernapasan buteyko mencegah tingkat keparahan asma, meningkatkan perbaikan PEFR dan kontrol asma yang di ukur dengan asthma control questionare (ACQ). Teknik pernapasan buteyko juga terbukti meningkatkan kualitas hidup (Prem, Sahoo, \& Adhikari, 2013). Menurut Cowie, Conley, Underwood, dan Reader (2008), teknik pernapasan buteyko dapat mengurangi penggunaan terapi kortikosteroid inhalasi. Dari beberapa literatur, tidak terdapat efek samping yang dilaporkan dalam kelompok yang diberikan intervensi teknik pernapasan buteyko.

Pada penelitian sebelumnya pengukuran efek teknik pernapasan buteyko hanya dilakukan setelah 5 minggu, sehingga tidak diketahui efek teknik pernapasan buteyko setiap minggu dan tidak mendokumentasikan frekuensi latihan pernapasan buteyko yang dilakukan pasien dalam setiap minggunya. Dengan demikian menjadi lebih penting dilakukan penelitian ulang untuk mengetahui dan mengidentifikasi pengaruh buteyko terhadap kontrol asma pada minggu pertama, kedua, ketiga dan keempat, serta frekuensi latihan pernapasan buteyko yang dilakukan pasien setiap minggunya, sehingga akan menjadi lebih jelas berapa kali teknik pernapasan buteyko dilakukan pada pasien asma. Pada hasil penelitian sebelumnya bahwa teknik pernapasan buteyko tidak signifikan terhadap peningkatan nilai FEV1 (McHugh et al, 2003), sehingga perlu untuk melihat pengaruh teknik pernapasan buteyko secara objektif terhadap nilai spirometri (FEV1). Atas dasar tema sentral tersebut, maka penting untuk dilakukan penelitian ulang untuk mengetahui pengaruh teknik pernapasan buteyko terhadap kontrol asma. Adapun tujuan penelitian ini adalah untuk mengetahui pengaruh teknik pernapasan buteyko terhadap kontrol asma bronkial yang di ukur dengan menggunakan ACT (Asthma Control Test) dan Spirometri di Rumah Sakit Hasan Sadikin Bandung.

\section{BAHAN DAN METODE}

Penelitian quasi eksperimental dengan pendekatan pretest and post test one group design ini melibatkan 14 pasien asma yang dipilih dari Poli Paru RSUP Dr. Hasan Sadikin Bandung dengan consecutive sampling. Penelitian ini dilakukan di Poli Paru Rumah Sakit Hasan Sadikin Bandung ini dilakukan dari tanggal 20 Juni sampai 24 Juli 2017. Kontrol asma diukur dengan menggunakan ACT (Asthma Control Test) secara time series artinya diukur pada saat pretest, minggu pertama, kedua, ketiga, dan keempat. Selain itu dilakukan pemeriksaan objektif dengan menggunakan spirometri (nilai FEV1) yang diukur sebelum (pretest) dan setelah diberikan teknik pernapasan buteyko pada minggu ke empat. Data yang terkumpul dianalisis secara deskriptif dan inferensial yaitu dengan menggunakan uji repeated ANOVA dan dilanjutkan analisis uji Post Hoc serta dilakukan juga uji paired $T$-Test dengan skala signifikansi $p<0,05$.

\section{HASIL PENELITIAN}

Karakteristik responden dalam penelitian ini adalah responden yang berusia 19 tahun sampai 65 tahun, dengan rata-rata usia 44 tahun. Sebagian besar responden perempuan, memiliki riwayat alergi, dan riwayat genetik. 
Hasil penelitian menunjukkan adanya perbedaan rerata yang signifikan lebih tinggi antara skor ACT setelah diberikan teknik pernapasan buteyko $(19,79 \pm 1,47)$ dengan skor ACT pada minggu III $(17,50 \pm 1,78)$, minggu II $(12,64 \pm 1,82)$, minggu I $(9,57 \pm 1,95)$, dan pretest $(7,64 \pm 1,82)$. Post hoc analisis menemukan skor post test minggu ke empat $(19,79 \pm 1,47)$ signifikan lebih baik daripada posttest minggu III $(17,50 \pm 1,78)$, minggu II $(12,64 \pm 1,82)$, minggu I $(9,57 \pm 1,95)$, dan pretest $(7,64 \pm 1,82)$ dalam meningkatkan kontrol asma. Uji paired ttest menunjukkan terdapat rerata nilai FEV1 setelah diberikan teknik pernapasan buteyko signifikan lebih tinggi daripada skor sebelum diberikan teknik pernapasan buteyko.

\section{PEMBAHASAN}

Berdasarkan hasil di atas diketahui penelitian ini membuktikan bahwa teknik pernapasan buteyko berpotensi untuk memberikan pengaruh positif terhadap kontrol asma bronkial baik secara objektif maupun subjektif. Pengaruh positif teknik pernapasan buteyko juga didukung dengan adanya data yang menunjukkan bahwa hasil dari post test ACT dan FEV1. Berdasarkan perhitungan hasil uji paired $\mathrm{t}$ test didapatkan rerata nilai skor ACT pada responden sebelum diberikan latihan teknik pernapasan buteyko sebesar 7,64 $(1,823)$ dan setelah diberikan latihan pernapasan buteyko rerata menjadi 19,79 dengan nilai $p$ value $<0,05$ artinya, terdapat perbedaan antara skor ACT sebelum dan setelah diberikan teknik pernapasan buteyko. Hasil penelitian ini menunjukkan bahwa ada perbedaan rerata skor ACT sebelum dan sesudah latihan teknik pernapasan buteyko selama 4 minggu. Hal ini dikarenakan teknik pernapasan buteyko merupakan teknik yang menggabungkan pernapasan melalui hidung, pernapasan diafragma dan control pause.

Menurut Bruton \& Lewith (2005) bahwa teknik bernapas melalui hidung dapat menghangatkan, memfiltrasi, dan melembabkan udara yang masuk. Pernapasan hidung dapat meningkatkan kadar oksida nitrat (Villareal et al, 2014). Pernapasan hidung lebih baik daripada pernapasan mulut. Alergen yang menyebabkan bronkospasme sehingga pasien mengalami sesak napas. Respon alami pasien dengan keadaan sesak napas yaitu mencoba bernapas lebih dalam melalui mulut, sehingga menghirup lebih banyak alergen dan memicu bronkospasme lebih lanjut (Bruton \& Lewith, 2005).

Salah satu mekanisme biokimia teknik pernapasan buteyko melalui pengaruhnya terhadap oksida nitrat (NO). Sebagian besar respon fisiologisnya terhadap bronkodilasi, vasodilatasi, permeabilitas jaringan, sistem imun, transportasi oksigen, respon insulin, memori dan mood. Oksida nitrat dihasilkan dari sinus paranasal (Courtney, 2008). Sedangkan toraks dan diafragma mengubah tekanan dalam toraks untuk menghasilkan gerakan udara. Pada saat inspirasi, kubah diafragma mendatar dan sangkar rusuk terangkat. Kontraksi diafragma dan otot interkostal eksterna menarik rusuk ke atas dan ke depan sehingga meningkatkan diameter transversal dan anteroposterior. Seiring dengan peningkatan volume dada dan paru, tekanan alveolar menurun dan udara tertarik ke paru. Toraks yang tambah luas membuat tekanan intrapleural menjadi negatif yang akan memperluas paru (Black \& Hawks, 2014). 
Control pause memberikan manfaat untuk memberikan mengurangi hiperventilasi. Control pause dapat di ukur dalam hitungan detik dan diyakini dapat meningkatkan kesehatan. Pada saat melakukan control pause, hidung ditutup dengan jari di akhir exhalasi dan hitung BTH (breathing holding time) dalam beberapa detik. Pasien harus menutup hidung sampai ada keinginan untuk bernapas. Kemudian melakukan inspirasi dan ekspirasi seperti normal kembali. Ketika melakukan exhalasi, maka mulut harus dalam keadaan tertutup (Rakhimov, 2013).

Metode buteyko mengembangkan kemampuan meningkatkan control pause. Praktisi buteyko secara konsisten melaporkan control pause yang lebih lama dihubungkan dengan penurunan gejala asma. Selain itu control pause berguna untuk meningkatkan $\mathrm{CO} 2$ pada pasien asma yang kehilangan $\mathrm{CO} 2$ akibat hiperventilasi yang terus menerus. Dengan melalukan control pause akan mengatur ulang ritme pernapasan yang abnormal atau mengatur ulang pusat pernapasan otak sehingga kurang sensitif terhadap $\mathrm{CO} 2$ (Courtney, 2008).

Menurut Black \& Hawks (2014) bahwa toraks dan diafragma mengubah tekanan dalam toraks untuk menghasilkan gerakan udara. Gerakan udara bergantung pada perbedaan tekanan antara atmosfer dan udara paru, dengan aliran udara dari daerah dengan tekanan tinggi ke daerah dengan tekanan rendah. Pada waktu inspirasi, kubah diafragma mendatar dan sangkar rusuk terangkat. Seiring dengan peningkatan volume dada dan paru, tekanan alveolar menurun dan udara tertarik ke paru (Black \& Hawks, 2014).
Penelitian ini di dukung oleh Hassan, Riad, dan Ahmed (2012), didapatkan bahwa teknik pernapasan buteyko mencegah tingkat keparahan asma, meningkatkan perbaikan PEFR dan kontrol asma yang di ukur dengan asthma control questionare (ACQ). Menurut Cowie, Conley, Underwood, dan Reader (2008), teknik pernapasan buteyko dapat mengurangi penggunaan terapi kortikosteroid inhalasi. Pada penelitian ini, teknik pernapasan buteyko diberikan secara berkelanjutan setiap dua kali dalam seminggu selama 4 minggu. Hal tersebut disesuaikan dengan alat ukur kontrol asma yang mengukur kontrol asma setelah 4 minggu.

Responden diberikan latihan teknik pernapasan buteyko selama 5-15 menit di Poli Paru Rumah Sakit Hasan Sadikin yang diajarkan oleh peneliti. Kemudian responden di sarankan untuk melakukan latihan teknik pernapasan buteyko minimal dua kali setiap minggu selama 4 minggu, dimana setiap latihan harus melakukan minimal 15 menit sampai 60 menit. Hal ini sesuai dengan tujuan dari pemberian terapi nonfarmakologi untuk mencapai gaya hidup yang normal, menghindari serangan, dan mengembalikan fungsi paru yang optimal (Bruurs, Van Der Giessen, \& Moed, 2013). Teknik pernapasan buteyko ini terbukti aman dan mudah dilakukan (Hassan et al, 2012). Teknik pernapasan ini dapat menurunkan gejala asma, dan penggunaan obat-obatan (Cooper et al., 2003). Hal ini didukung oleh Solomen dan Aaron (2016), latihan pernapasan meningkatkan volume paru, pertugaran gas, mengontrol sesak napas, dan membantu membersihkan sekresi.

Menurut Cooper et al (2003), teknik pernapasan buteyko merupakan 
teknik olah napas yang dikembangkan khusus untuk pasien asma bronkial. Pada pasien asma mengalami hiperventilasi sebagai kompensasi tubuh agar tidak kehilangan kadar karbondioksida yang akan berdampak pada gangguan $\mathrm{pH}$ dan berkurangnya kadar oksigen dalam jaringan. Dengan diberikan teknik pernapasan buteyko dapat meningkatkan jumlah oksigen. Menurut Courtney (2007) bahwa teknik pernapasan buteyko menggunakan kontrol napas dan latihan menahan nafas untuk mengobati berbagai kondisi kesehatan yang berhubungan dengan hiperventilasi dan karbon dioksida rendah.

Perbaikan kontrol asma pada responden yang telah diberikan latihan pernapasan buteyko memiliki signifikansi yang kuat baik secara subjektif maupun objektif. Hal ini menunjukkan bahwa perbaikan tidak hanya meningkatkan skor kontrol asma secara signifikan namun juga mampu memperbaiki FEV1 berdasarkan hasil ukur spirometri. Rerata nilai skor FEV1 pada responden sebelum diberikan latihan teknik pernapasan buteyko sebesar 37,43 dan setelah diberikan latihan pernapasan buteyko rerata menjadi 69,57. Hasil penelitian ini menunjukkan bahwa terdapat perbedaan rerata nilai FEV1 sebelum dan sesudah latihan teknik pernapasan buteyko selama 4 minggu. Hasil penelitian ini bertolak belakang dengan hasil penelitian yang dilakukan oleh McHugh et al (2003) bahwa teknik pernapasan buteyko tidak signifikan dalam meningkatkan FEV1.

Keberhasilan perlakuan tersebut mungkin terjadi dikarenakan beberapa faktor dari perlakuan yang diberikan, salah satunya adalah frekuensi latihan teknik pernapasan buteyko. Berdasarkan hasil uji
Levene's test Equality Of Variancesdidapatkan nilai $\mathrm{p}$ value $=0,191$, artinya kedua data homogen/variansnya sama. Data dibagi menjadi kelompok yang melakukan latihan pernapasan buteyko 2-3 kali dalam seminggu dan kelompok yang melakukan teknik pernapasan buteyko lebih dari 3 kali dalam seminggu. Hasil uji T-Independent didapatkan nilai $\mathrm{p}$ value $=0,002$ artinya terdapat perbedaan ACT antara kelompok yang melakukan hanya 2-3 kali latihan teknik pernapasan buteyko dengan kelompok yang melakukan teknik pernapasan buteyko lebih dari 3 kali dalam seminggu.

Selain itu di dukung juga dengan hasil uji korelasi. Hasil uji korelasi skor ACT berdasarkan frekuensi latihan pernapasan buteyko dengan nilai $\mathrm{p}=0,001$, artinya terdapat hubungan antara frekuensi latihan pernapasan buteyko terhadap kontrol asma. Begitu juga dengan hasil uji korelasi nilai FEV1 berdasarkan frekuensi latihan pernapasan buteyko dengan nilai $\mathrm{p}=0,000$, artinya terdapat hubungan antara frekuensi latihan dengan nilai FEV1.

Selain itu faktor lain yang mempengaruhi kontrol asma yaitu terapi farmakologi. Pasien asma yang kontrol secara rutin di Poli Paru RSHS mendapatkan terapi farmakologi seperti pemberian bronkodilator. Hal ini merupakan pengobatan utama dalam mengatasi serangan asma. Selain itu penggunaan dosis atau frekuensi konsumsi bronkodilator ataupun kortikosteroid termasuk dalam domain asma kontrol tes (ACT). Hal sesuai dengan Fm, M, Greenstone, dan $\mathrm{Tj}$, (2010) bahwa penatalaksanaan asma bronkial yaitu dengan pemberian terapi farmakologi, karena dapat membantu mengurangi atau meredakan serangan asma bronkial, seperti 
terapi bronkodilator, kortikosteroid. Kombinasi kedua obat tersebut (Long acting 32 agonist+inhaled kortikosteroid) terbukti efektif untuk menangani penyakit asma bronkial karena kedua obat ini dapat mengurangi eksaserbasi dan memperbaiki fungsi paru. Selain itu kombinasi ICS/long acting $\beta 2$ agonis lebih banyak disukai orang dewasa.

Menurut Higashi, Zhu, Stafford, dan Alexander (2011), terjadi peningkatan penggunaan steroid inhalasi dan kombinasi steroid/long acting $\beta 2$-agonis digunakan bertepatan dengan penurunan morbiditas dan mortalitas asma. Selain itu menurut Bedouch, Marra, FitzGerald, Lynd, \& Sadatsafavi, (2012) bahwa pemberian farmakologi seperti kombinasi terapi inhalasi kortikosteroid/long acting betaagonist telah menjadi komponen penting dari biaya asma. Kontrol asma yang buruk disebabkan oleh kesalahan dalam teknik penggunaan inhaler, kepatuhan (compliance), lingkungan (environment) (Black \& Hawks, 2014).

Pada penelitian ini tampak perbaikan kontrol asma dimulai pada minggu ketiga sampai minggu ke empat selama melakukan teknik pernapasan buteyko. Hal ini bertolak belakang dengan penelitian yang dilakukan oleh dilakukan oleh Cooper et al (2003), menggambarkan bahwa terjadi perbaikan gejala asma, pengurangan dosis beta agonis pada pasien asma setelah diberikan 6 bulan intervensi pernapasan buteyko. Namun sejalan dengan penelitian yang dilakukan oleh Villareal et al., (2014), dimana hasil penelitiannya menunjukkan perbaikan kualitas hidup pada minggu ke empat diberikan latihan pernapasan buteyko.

Teknik pernapasan buteyko dapat menurunkan penggunaan bronkodilator, dan steroid inhalasi. Hal ini sesuai dengan penelitian yang dilakukan oleh Mchugh et al (2003). Penggunaan bronkodilator termasuk dalam kategori dalam menentukan kontrol asma. Pada hasil kuisioner ACT tampak responden yang mengalami perbaikan gejala di ikuti dengan pengurangan penggunaan bronkodilator dari 3 kali per hari menjadi 1-2 kali dalam satu bulan.

Pada saat penelitian, terdapat 1 responden yang mengalami kekambuhan pada mingggu ke empat latihan dikarenakan alergi. Rumah responden tersebut sedang di renovasi, sehingga banyak debu-debu. Klien mengaku memiliki riwayat alergi terhadap debu yang memicu terjadinya kekambuhan asma. Oleh karena klien tidak melakukan latihan teknik pernapasan buteyko sehingga di drop out oleh peneliti. Menurut Crocker et al (2016), eksaserbasi asma dipicu oleh alergen dalam rumah terutama pada keluarga yang belum mendapatkan pendidikan kesehatan. Lingkungan rumah terkait erat dengan kesehatan penghuninya. Alergen dalam ruangan seperti debu rumah, tungau, kecoa berisiko mengembangkan asma. Kualitas perumahan yang buruk sangat terkait dengan kontrol asma yang buruk.

Adapun keterbatasan penelitian ini adalah faktor lain yang dapat mempengaruhi kontrolasma, salah satunya adalah farmakologi, baik bronko dilator maupun kortikosteroid. Namun peneliti tidak melakukan pengukuran terhadap ketepatan responden dalam menggunakan obat-obatan inhalasi. Berdasarkan fenomena selama penelitian, ditemukan pasien asma bronkial yang sudah melakukan kontrol berulang tetapi belum mengerti dan masih salah dalam 
menggunakanobat-obat inhaler. Selain itu terdapat responden tidak patuh dalam melakukan latihan teknik pernapasan buteyko, sehingga sebelum penelitian dimulai atau pada saat melakukan screening responden diharapkan untuk melakukan tes prediksi kepatuhan responden terhadap kegiatan yang dilakukan.

Keunggulan penelitian dalam penelitian ini adalah desain time series memberikan keuntungan tersendiri terhadap penelitian ini. Keuntungan tersebut adalah peneliti dapat melihat secara detail perkembangan rerata skor ACT pada setiap minggu selama 4 minggu dan penelitian ini di dukung dengan hasil objektif yaitu nilai FEV1 yang meningkat signifikan setelah dilakukan evaluasi.

\section{KESIMPULAN DAN SARAN}

Kesimpulan dalam penelitian ini adalah terdapat pengaruh latihan teknik pernapasan buteyko terhadap kontrol asma bronkial. Hal ini dipengaruhi oleh banyak hal, seperti penggunaan bronkodilator, kortikosteroid, frekuensi latihan teknik pernapasan buteyko, dan lingkungan. Oleh karena itu perlu dilakukan eksplorasi lebih lanjut mengenai pengaruh teknik pernapasan buteyko terhadap kontrol asma dengan jumlah sampel yang lebih besar, waktu penelitian yang lebih panjang, dan edukasi tentang cara pemakaian inhaler, frekuensi latihan pernapasan yang lebih sering atau setiap hari dan durasi yang lebih lama.

\section{DAFTAR PUSTAKA}

Ai, K., Hoang, T., \& Nguyen, H. M. (2015). The Effectiveness of Practicing Pranayama Yoga on Some Respiratory Indicators in
Patients Suffering from Bronchial Disease, 3(June), 6-12.

Bateman, E. D., Hurd, S. S., Barnes, P. J., Bousquet, J., Drazen, J. M., FitzGeralde, M., ... Zar, H. J. (2008). Global strategy for asthma management and prevention: GINA executive summary. European Respiratory Journal, 31(1), 143-178. http://doi.org/10.1183/09031936. 00138707

Bedouch, P., Marra, C. A., FitzGerald, J. M., Lynd, L. D., \& Sadatsafavi, M. (2012). Trends in AsthmaRelated Direct Medical Costs from 2002 to 2007 in British Columbia, Canada: A Population Based-Cohort Study. PLoS ONE, $7(12)$.

http://doi.org/10.1371/journal.pon e.0050949

Bruton, A., \& Lewith, G. T. (2005). The Buteyko breathing technique for asthma: A review. Complementary Therapies in Medicine, 13(1), 41-46. http://doi.org/10.1016/j.ctim.2005. 01.003

Bruurs, M. L. J., Van Der Giessen, L. J., \& Moed, H. (2013). The effectiveness of physiotherapy in patients with asthma: A systematic review of the literature. Respiratory Medicine, 107(4), 483-494.

http://doi.org/10.1016/j.rmed.201 2.12.017

Cooper, S., Oborne, J., Newton, S., Harrison, V., Coon, J. T., Lewis, S., \& Tattersfield, A. (2003). T 1999, 674-680. 
Courtney, R. (2007). Strengths , Weaknesses, and Possibilities of the Buteyko Breathing Method. Biofeedback, 36(2), 59-63. Retrieved from http://www.resourcenter.net/imag es/AAPB/Files/Biofeedback/2008 /biof_summer_buteyko_breathing. pdf

Cowie, R. L., Conley, D. P., Underwood, M. F., \& Reader, P. G. (2008). A randomised controlled trial of the Buteyko technique as an adjunct to conventional management of asthma. Respiratory Medicine, 102(5), 726-732. http://doi.org/10.1016/j.rmed.200 7.12.012

Crocker, D. D., Kinyota, S., Dumitru, G. G., Ligon, C. B., Herman, E. J., Ferdinands, J. M., ... Sipe, T. A. (2016). Effectiveness of HomeBased, Multi-Trigger, Multicomponent Interventions with an Environmental Focus for Reducing Asthma Morbidity. American Journal of Preventive Medicine, 41(2), S5-S32. http://doi.org/10.1016/j.amepre.20 11.05.012

Dal Negro, R. W., Micheletto, C., Tosatto, R., Dionisi, M., Turco, P., \& Donner, C. F. (2007). Costs of asthma in Italy: Results of the SIRIO (Social Impact of Respiratory Integrated Outcomes) study. Respiratory Medicine, 101(12), 2511-2519. http://doi.org/10.1016/j.rmed.200 7.07.011

Ducharme, F., \& Chauhan, B. (2014). Anti-leukotriene agents compared to inhaled corticosteroids in the management of recurrent and / or chronic asthma in adults and children ( Review ). Cochrane Database of Systematic Reviews, (4).

http://doi.org/10.1002/14651858. CD002314.pub3.Anti-leukotriene Fm, D., M, N. C., Greenstone, I., \& Tj, L. (2010). Addition of long-acting beta2-agonists to inhaled steroids versus higher dose inhaled steroids in adults and children with persistent asthma ( Review ) Addition of long-acting beta2agonists to inhaled steroids versus higher dose inhaled steroids in adult. The Cochrane Library, (4), 2-4.

http://doi.org/10.1002/14651858. CD005533.pub2.Copyright

Global Asthma Network. (2014). The Global Asthma Report 2014 (Vol. 5). http://doi.org/ISBN: 978-0473-29125-9978-0-473-29126-6 (ELECTRONIC)

Hassan, Z. M., Riad, N. M., \& Ahmed, F. H. (2012). Effect of Buteyko breathing technique on patients with bronchial asthma. Egyptian Journal of Chest Diseases and Tuberculosis, 61(4), 235-241. http://doi.org/10.1016/j.ejcdt.2012. 08.006

Heikkinen, S. A. M., Quansah, R., Jaakkola, J. J. K., \& Jaakkola, M. S. (2012). Effects of regular exercise on adult asthma. European Journal of Epidemiology, 27(6), 397-407. http://doi.org/10.1007/s10654012-9684-8

Higashi, A., Zhu, S., Stafford, R. S., \& Alexander, G. C. (2011). National 
Trends in Ambulatory Asthma

Treatment , 1997 - 2009, 14651471.

http://doi.org/10.1007/s11606011-1796-4

Kullowatz, A., Kanniess, F., Dahme, B., Magnussen, H., \& Ritz, T. (2007). Association of depression and anxiety with health care use and quality of life in asthma patients. Respiratory Medicine, 101(3), 638-644.

http://doi.org/10.1016/j.rmed.200 6.06 .002

Li, J. T., Oppenheimer, J., Bernstein, I. L., Nicklas, R. A., Khan, D. A., Blessing-Moore, J., ... Wallace, D. V. (2005). Attaining optimal asthma control: A practice parameter. Journal of Allergy and Clinical Immunology, 116(5), 1-9. http://doi.org/10.1016/j.jaci.2005. 08.017

Masoli, M., Fabian, D., Holt, S., \& Beasley, R. (2004). The global burden of asthma: Executive summary of the GINA Dissemination Committee Report. Allergy: European Journal of Allergy and Clinical Immunology, 59(5), 469-478. http://doi.org/10.1111/j.13989995.2004.00526.x

Mchugh, P., Aitcheson, F., Duncan, B., \& Houghton, F. (2003). THE NEW ZEALAND intervention, 116(1187), 1-7.

P, J. M., D, M. R., U, A. A., \& A, M. A. (2013). Yoga versus Physiotherapy : Effect on Pulmonary function , Breath Holding Time \& Quality of Life in Asthmatics, 7(4), 160-167.
Penelitian, B., \& Pengembangan, D. A. N. (2013). Riset Kesehatan Dasar. http://doi.org/10.1007/s13398-

014-0173-7.2

Prem, V., Sahoo, R. C., \& Adhikari, P. (2013). Comparison of the effects of Buteyko and pranayama breathing techniques on quality of life in patients with asthma - a randomized controlled trial. Clin Rehabil, 27(2), 133-141. http://doi.org/10.1177/026921551 2450521

Rakhimov, A. (2013). Advanced Buteyko Breathing Exercises.

Solomen, S., \& Aaron, P. (2016). Breathing techniques-A review 25 different types Breathing techniques- A review, 1(October 2015).

Thomas, S. (2004). Buteyko: A useful tool in the management of asthma? International Journal of Therapy and Rehabilitation, 11(10), 476479.

http://doi.org/10.12968/ijtr.2004.1 1.10 .17190

To, T., Stanojevic, S., Feldman, R., Moineddin, R., Atenafu, E. G., Guan, J., \& Gershon, A. S. (2013). Is asthma a vanishing disease? A study to forecast the burden of asthma in 2022. BMC Public Health, 13(1), 254. http://doi.org/10.1186/1471-245813-254

Villareal, G. M. C., Villazor, B. P. U., Villegas, A. M., Visaya, S. N., Vista, M. E., Tan, C. B., \& G, C. E. (2014). Health and Medicine Effect of Buteyko Method on Asthma Control and Quality of 
Life of Filipino Adults with

Bronchial Asthma, 2(1), 44-60. 